complications occurred. None of the mothers had been offered vaccination against pertussis during pregnancy.

The epidemiology of pertussis is changing in Italy as well as in other countries with high vaccination coverage. The disease is now increasing as an incidence in adolescents (and adults) who have lost their immune protection, and especially in new-born infants who have not started or completed the primary vaccination course yet. The data from the European Annual Epidemiological Report for 2016 report the highest notification rate in children $<1$ year $(73.6$ cases per 100,000 population), similar to that observed in 2015 (73.1). The vaccination of pregnant women against pertussis is considered an effective and available preventive option adopted for some years and in a systematic way in different international contexts. Also in Italy, in the 2017-2019 National Vaccination Plan there is a recommendation to recall in pregnancy the immunization from pertussis with the trivalent vaccine (whooping cough, tetanus and diphtheria). The period indicated is between the 27 th and the 36 th week, ideally around the 28th week. The vaccine strategy for pertussis in pregnant women is effective in reducing neonatal deaths due to the disease, the need for hospitalization and the severity of the infection in infants under the age of 3 months. The vaccine does not pose any risk for pregnant women and newborns.

From the description of our experience, of the 6 cases of hospitalized pertussis in just 3 months in a Pediatric department, 5 could be theoretically prevented by vaccination of the mother. The reported narrative experience testifies indirectly the resurgence of the cases of pertussis in a period when the newborn and the infant is most at risk to contract the disease and to have severe complications.

Despite the available evidence and the consolidated experiences carried out, the application of this strategy, in some industrialized countries (including Italy), although recommended, it results largely sub-optimal. Pertussis prevention in newborns and infants is an urgent measure of public health.

\section{P305 HEALTHY LIFE-STYLE FOR A HEALTHY CHILDHOOD - A PROGRAM OF EDUCATION FOR HEALTH IN CHILDREN}

'2nd Paediatric Clinic University of Medicine and Pharmacy „Illiu Hatieganu', Cluj-Napoca, Romania; ${ }^{2}$ Romanian Society of Social Paediatrics, Cluj-Napoca, Romania; ${ }^{3}$ Society of Physicians from Children and Youth Communities, Cluj-Napoca, Romania; ${ }^{4}$ Regina Maria Healthcare Network, Cluj-Napoca, Romania

\subsection{6/archdischild-2019-epa.654}

Introduction Non-communicable diseases (NCDs) account for $70 \%$ of global mortality and represent the leading cause of death and disability worldwide. In Romania, the cardiovascular diseases represent the first cause of mortality. Unhealthy behavior, malnutrition, both overweight or obesity, and physical inactivity are known risk factors for metabolic syndrome, which is involved as a cause for cardiovascular diseases in adults. The education for health in children is one of the most effective ways to reduce exposure to risk factors for NCDs and decrease the morbidity in the future adults.

"Healthy Life-style for a Healthy Childhood - A Healthy Child is A Happy Child!' is a program for education for health for children developed under the NCD Child Advocacy in Action Grant Program of the American Academy of Pediatrics. The goal of this program was to promote the healthy life-style for children of three schools from Cluj-Napoca, Romania. The objectives were education for healthy lifestyle in school-aged children (by publication of brochures, live courses about the importance of healthy lifestyle: nutrition, physical activity, healthy behaviors), promotion of healthy nutrition (including workshops with healthy cooking where children and their parents prepare different healthy meals) and promoting of physical activity (running events for children involved in the program).

The website of the program contains online courses accessible for children involved in the program, but also to other children of school-age, being produced in three languages (Romanian, Hungarian and English). There are modules about healthy life-style and nutrition, including quizzes, one collection of recipes for healthy meals where the children could promote theirs healthy recipes. The children involved in the project could participate in one running event and then one team represented the project in the main running event in our city.

Based on the experience gained in this project all the activities will continue during the following years with an extension in other schools from our city, for a larger number of school-aged children.

Conclusions The education for health, promoting the change of the life-style of our children with a healthier one is considered the most beneficial preventive action in order to have a healthy population in the future and to decrease the risk for metabolic syndrome and cardiovascular disorders.

\section{P306 ENVIRONMENTALLY DEPENDENT ENDOCRINOPATHIES IN THE CHILDREN FROM MOUNTAINOUS REGION}

${ }^{1}$ Olesya Horlenko*, ${ }^{1}$ Lyubov Pushkash, ${ }^{1}$ Vikroria Studeniak, Marianna Peresta 1 , ${ }^{1}$ Valeria Brych, ${ }^{1}$ Ivan Pushkash, ${ }^{2}$ Natalia Banadyga. 'Uzhhorod National University, Uzhhorod, Ukraine; ${ }^{2}$ Ternopil State Medical University, Ternopil, Ukraine

\subsection{6/archdischild-2019-epa.655}

Background The problem of iodine deficiency diseases (IDD) is relevant in connection with the significant occurrence of iodine deficiency among the population of many countries of the world, an increase in morbidity with a wide range of clinical manifestations and a marked tendency to increase the incidence and severity among children of all age groups.

Material and methods The research was conducted on the basis of the data of the preventive survey (187 children) living in the ecologically dependent biogeochemical endemic zone with iodine deficiency in the mountain region of the Transcarpathian region in the period of 2014-2015y.y.

Result Taking into account the morphometric characteristics of the thyroid gland in the chidren was found a slight difference between the standard values of unchanged parenchyma thyroid gland, the size of the gland was on $24.4 \%$ lower than the reference in the girls and on $27.5 \%$ in the boys in the patients with hypoplasia., The size of the thyroid gland of children with the hyperplasia was higher than the reference on $39.04 \%$ in the girls and on $31.8 \%$ in the boys. The data of the state of the thyroid system testify have differences in the levels of TSH - from $2.87 \pm 0.67 \mathrm{mO} / 1$ to $1.89 \pm 0.43$ $\mathrm{mO} / \mathrm{l}, \mathrm{p}=1.97 \times 10-8$, respectively, in groups in children with hyperplasia of the thyroid gland and with normal thyroid parenchyma. The levels of AT-TG are higher than the reference in children with thyroid hyperplasia and within the normal range in children with normal thyroid gland parenchyma, which suggests insignificant effects on the interference with the physiological process of T3 and T4 synthesis. The value 